\author{
Economics Working Paper Series
}

2021/010

\title{
Investment Shocks: the Labour Wedge and the Comovement Problem
}

\author{
Benjamin Caswell \\ The Department of Economics \\ Lancaster University Management School \\ Lancaster LA1 4YX \\ UK
}

(C) Authors

All rights reserved. Short sections of text, not to exceed two paragraphs, may be quoted without explicit permission, provided that full acknowledgement is given. 


\title{
Investment Shocks: the Labour Wedge and the Comovement Problem
}

\author{
Benjamin Caswell*
}

August 11, 2021

\begin{abstract}
Shocks to the marginal efficiency of investment (MEI) play a significant role in business cycle fluctuations. However, in standard quantitative models, positive (negative) MEI shocks tend to cause consumption to fall (rise) on impact while investment rises (falls). This conflicts with the well-established observation that consumption and investment are both procyclical and move together over the business cycle. This paper demonstrates that MEI shocks can generate positive comovement between consumption and investment in a standard RBC framework through the inclusion of a time-varying labour wedge. This allows for tractable analytical expressions, and straightforward graphical interpretations, which describe the subset of the parameter space where positive comovement is achieved.
\end{abstract}

Keywords: comovement problem; investment shocks; labour wedge; business cycles

JEL Classiflcation: E27; E32

\section{Introduction}

Studies suggest that shocks to the marginal efficiency of investment (MEI) play a significant role in business cycle fluctuations. For example, Greenwood, et al (2000) find that investment shocks explain $30 \%$ of the fluctuations in output and one-quarter of the fluctuations in hours. Moreover, Fisher (2006) determines that these shocks are responsible for $36-47 \%$ of the fluctuations in output and $42-67 \%$ of the fluctuations in hours. Similarly, Justiniano, et al. (2010) find that between $50 \%$

\footnotetext{
*b.caswell@lancaster.ac.uk Lancaster University Management School, Lancaster, LA1 4YX, UK
} 
and $60 \%$ of fluctuations in output and hours can be attributed to investment shocks. However, in typical structural models, a positive (negative) shock to the marginal efficiency of investment tends to cause consumption to fall (rise) on impact while investment rises (falls). This conflicts with well-established observations which show that both consumption and investment move together and are pro-cyclical over the business cycle. This discrepancy between model and data is known in the literature as the comovement problem.
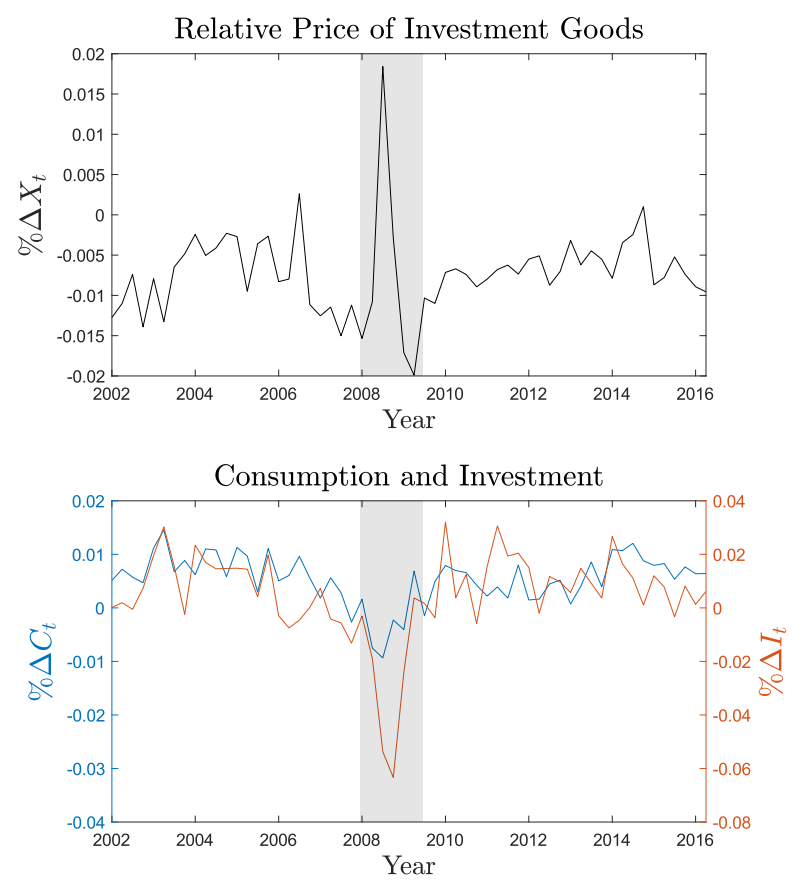
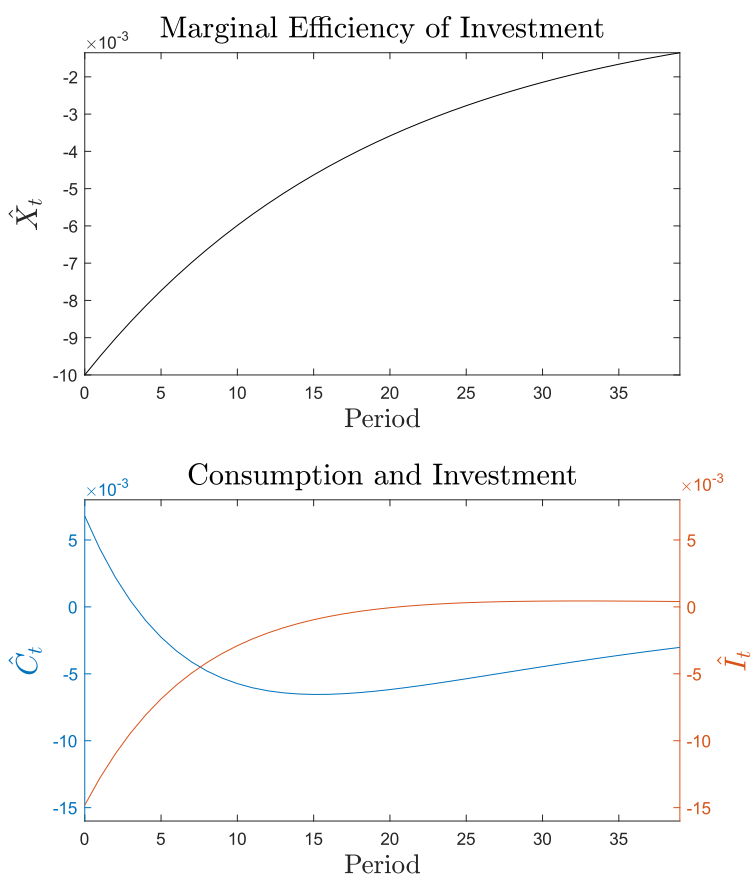

Figure 1: US Data and Impulse Response Functions

Figure 1 provides a quick illustration of the comovement problem. The two panels on the left display US data while the two panels on the right show the impulse response functions generated by a negative MEI shock in standard RBC model (with benchmark parameter values). Where increases in the relative price of investment goods can be interpreted as negative shocks to the marginal efficiency of investment, the top left panel displays a negative MEI shock during the Great Recession (denoted by the grey bar). The bottom left panel displays the quarterly growth rates of consumption and investment over the same period. It can be seen in the data that both of these macroeconomic variables move together in association with the investment shock; the growth rates of consumption and investment both fall alongside an increase in the relative price of investment. 
In contrast, the bottom right panel shows model IRFs for consumption and investment with respect to a negative one percent MEI shock. It can be seen that the model generates opposing responses, consumption rises on impact while investment falls; in conflict with the observed data over the business cycle.

Therefore, investment shocks appear to play a large role in business cycle fluctuations, yet typical structural models do not generate the appropriate unconditional comovements between macroeconomic variables. The inability of a benchmark RBC model to generate an empirically recognisable business cycle; namely, the positive correlations observed between consumption, investment, output and hours in response to MEI shocks, may be indicative of spurious investment shock transmission mechanisms. This could be cause for concern when drawing inferences from benchmark structural models as MEI shocks clearly matter for business cycle fluctuations.

So, what causes the comovement problem to arise in a benchmark RBC model? A straightforward interpretation is that when investment in new capital goods is relatively cheaper, it becomes optimal to sacrifice some present consumption (and postpone leisure) in order to invest and obtain a higher level of (output and) consumption in the future. In other words, a fall in the relative price of investment goods causes the opportunity cost associated with leisure to rise. As a result, hours worked and output increase.

Ultimately, the immediate increase in output is insufficient to permit consumption and investment to rise together; consumption initially falls in response and comoves negatively (illustrated in Figure 2). Inter-temporal substitution (a pivot in the red budget constraint caused by a fall in the relative price of investment - A to B) dominates over intra-temporal substitution on impact (a parallel shift in the green budget constraint caused by an increase in hours/output - B to C). 


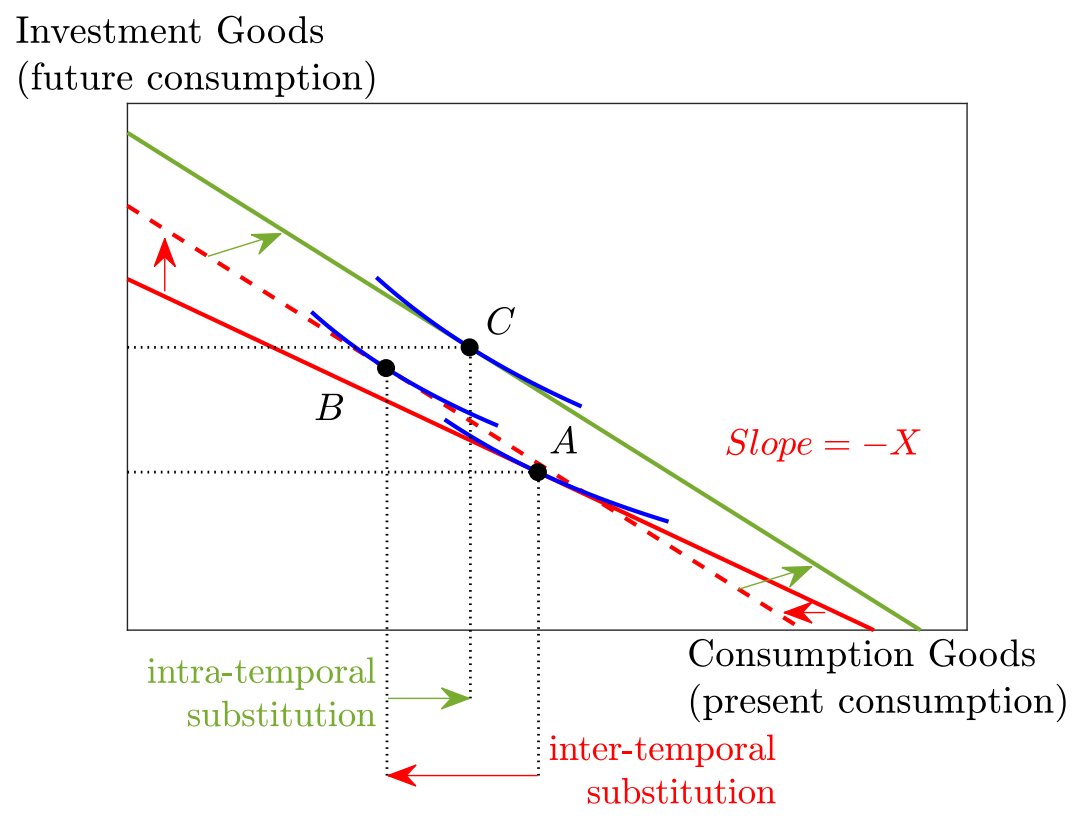

Figure 2: Diagrammatic Representation of the Comovement Problem

Therefore, the relative weakness of intra-temporal substitution generates cross-correlations which are at odds with macroeconomic data. How can this be resolved? Through strengthening the intra-temporal substitution channel via the inclusion of a time-varying labour tax wedge.

In fact, several studies point towards the importance of the labour wedge in propagating business cycles. For example, in the seminal work of Chari, et al, (2007) the labour wedge consistently accounts for a significant portion of the variation in post-war US output. Moreover, Zhang (2018) shows the labour wedge played a key role in aggregate fluctuation in the US during the Great Recession (in response to both TFP shocks and credit crunches).

Drawing on these results, following the method proposed by Karabarbounis (2014), empirical estimates of the labour wedge are constructed for the US economy and plot alongside output. ${ }^{1}$.

\footnotetext{
${ }^{1}$ Constructed using KPR preference specification (equation 16 in Karabarnbounis, 2014) with data and parameter values used Section 5
} 


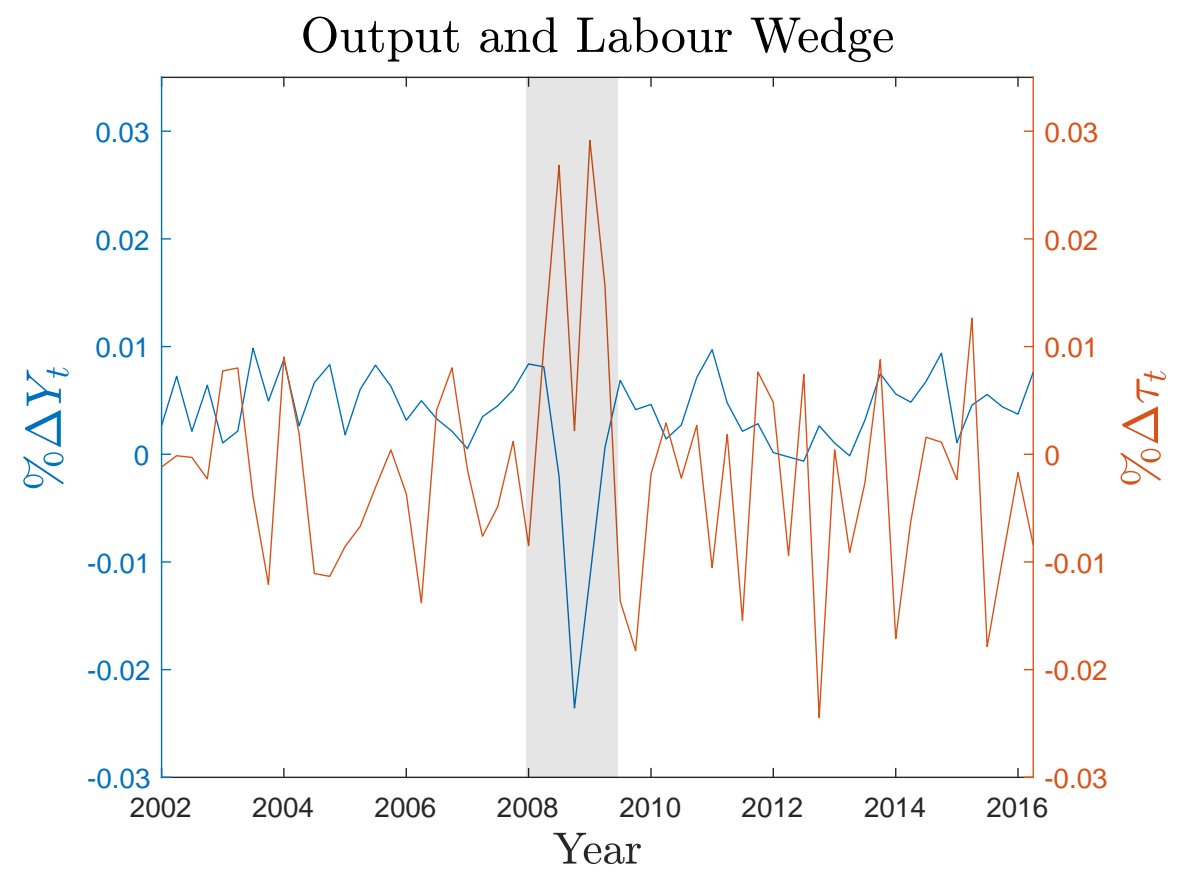

Figure 3: US Output and Labour Wedge

It can be seen from the data in Figure 3 that labour wedge and output growth move in opposite directions over the business cycle (correlation -0.65). Indeed, the significant counter-cyclicality of the labour wedge is a well-documented feature of the US labour market (see Shimer, 2009; Karabarbounis, 2014; Atesagaoglu and Elgin, 2014). Intuitively this could broadly be interpreted as search frictions or wage rigidities which fluctuate at business cycle frequencies.

In light of these findings, a counter-cyclical labour wedge mechanism is introduced into a standard RBC framework to resolve the comovement problem (detailed in section 3). Under this specification, both consumption and investment can rise contemporaneously in response to an investment shock; however, this only occurs under a subset of the parameter space where there is a sufficiently large increase in output on impact. The mechanism functions as follows: the only way of immediately increasing output in response to an MEI shock is through a rise in labour input (capital is a state variable and therefore fixed on impact while the MEI shock itself does not directly enter into the production function). As a consequence, the marginal product of labour always falls in response; thwarting the ability of labour to boost output.

The inclusion of a counter-cyclical labour wedge increases the volatility of hours worked and helps to offset the fall in the marginal product of labour. Following a shock to the marginal 
efficiency of investment, the labour wedge declines, which increases the 'post-tax' wage rate and encourages workers to supply more labour. This amplifies the intra-temporal substitution channel and further raises the response of output on impact (a shift in the green budget constraint which generates an optimal allocation above and to the right of point $\mathrm{A}$ in Figure 2).

While the comovement problem has been reconciled in the literature through a variety of approaches; typically employing some combination of nominal and real frictions or multiple sectors (for example, Khan and Tsoukalas, 2011; Eusepi and Preston, 2015; Ascari, et al, 2016; Chen and Liao, 2018), the advantage of the labour wedge setup here is three fold. Firstly, the inclusion of this mechanism captures two key observable features of the US labour market; a counter-cyclical labour wedge and improved fit in the volatility of hours worked. Secondly, by abstracting away from medium-scale frictions and multiple sectors, this paper allows for a comprehensive yet intuitive understanding of the comovement problem; the model permits tractable analytical expressions and straightforward graphical interpretations of the results. Thirdly, the parsimonious nature of the model limits the number of equilibrium equations. As a result, when estimating the model, fewer structural shocks are required; ipso facto this inhibits the use of ambiguous shocks with unclear interpretations for the purposes of avoiding stochastic singularity. A corollary is the elimination of potentially misspecified propagation mechanism, which often arise in larger medium-scale DSGE models with an extensive range of structural shocks (see Chari, et al, 2008; Grassi and LeonLedesma, 2018).

The remainder of this paper is structured as follows: Section 2 consists of a literature review. Section 3 reviews derives the model. Section 4 provides graphical interpretations and analytical expressions describing the key theoretical results. Section 5 estimates the model for the US economy. Section 6 concludes.

\section{Literature Review}

Consumption tends to moves counter-cyclically in response to positive MEI shocks in models with time-separable utility (Barro and King, 1984). A straightforward interpretation is that when investment in new capital goods is relatively cheaper, it becomes optimal to sacrifice some present 
consumption (and postpone leisure) in order to invest and obtain a higher level of output (and consumption) in the future. In other words, a fall in the relative price of investment goods induces inter-temporal substitution which usually dominates over intra-temporal substitution on impact (figure 2).

This puzzle has been reconciled in the literature through a variety of different approaches. For example, Greenwood, et al. (1988) show that it is possible to achieve positive comovement under a flexible price setup. Two key aspects enable their result; non-separable utility and capacity utilisation costs. Firstly, GHH preferences are adopted, which exhibit non-separability in consumption and leisure (labour supply depends on the wage rate but not consumption; there is no wealth effect). This shuts down the intertemporal substitution channel which causes consumption to fall on impact. Secondly, utilisation costs allow the capital stock to be worked with greater intensity at the expense of accelerated depreciation. This makes it possible for capital input to rise immediately without an increase in physical investment. As a result, the existing capital stock is worked with greater intensity on impact, mitigating the effect of diminishing returns to labour and further increasing output in response to the shock. This induces an outward shift in labour demand, which causes the wage rate and hours worked to increase. Subsequently, as there is no wealth effect, output rises along with consumption and investment. The primary disadvantage to this approach is that there is little empirical evidence (or a priori reasoning) which suggests that non-separability of consumption and leisure is a reasonable functional form to assume. The restrictive nature of GHH preferences has subsequently motivated studies which propose alternative ways of reconciling the comovement problem.

For example, in a medium-scale DSGE model, Khan and Tsoukalas (2011) demonstrate that comovement can be achieved with separable utility. Capacity utilisation with monopolistic competition and nominal rigidities are used to generate positive comovement. Nominal rigidities induce counter-cyclical wage and price mark-ups which result in an outward shift in labour demand in response to a positive investment shock. This leads to an amplified response in hours worked which causes output and consumption to rise on impact. Under this framework they emphasise that both GHH preferences and monopolistic competition with nominal rigidities are separately 
capable of generating this result; however, when estimating the model, the data clearly favours the latter explanation. The emphasis on the nominal rigidities channel over the weak intertemporal substitution channel also yields a superior fit for US data in terms of the second moments of consumption, output, and hours.

Furlanetto, et al (2013) propose a resolution to the comovement problem using rule-of-thumb consumers and nominal rigidities. In their setup, a portion of agents consists of rule-of-thumb consumers who do not engage in financial markets in order to smooth consumption; instead, each period they simply consume their entire income (they have a zero wealth effect). In response to a shock to the marginal efficiency of investment, it becomes optimal for agents to increase their hours worked and postpone leisure. Naturally, this leads to an increase in consumption for rule-of-thumb consumers since they do not invest. If the portion of rule-of-thumb consumers is sufficiently large (greater than approximately $25 \%$ of agents, given their specified parameter calibration), aggregate consumption rises on impact and comovement is achieved. Nominal rigidities helps reinforce positive comovement by dampening the intertemporal substitution effect; this enables the result to be achieved for a larger subset of the parameter space.

In a benchmark New Keynesian DSGE model with endogenous capital accumulation, Furlanetto and Seneca (2014) find that sufficient substitutability between leisure and consumption, along with nominal rigidities are key to resolving the comovement problem. They emphasise that GHH preferences generate comovement primarily due to the strong complementarity induced by nonseparability between leisure and consumption. Using a generalised additively-separable utility function, they demonstrate that the size of the wealth effect is largely unimportant for generating the appropriate comovement of macroeconomic variables. Instead, the size of intertemporal substitution determines the magnitude of the response, while the degree of complementarity between hours and consumption determines the sign of comovement on impact.

Eusepi and Preston (2015) construct a model with heterogeneity in consumption and labour. They establish that positive comovement hinges on the consumption differential between employed and non-employed agents, and their relative labour inputs. In this framework, each household consists of a continuum of agents, and labour market participation entails a fixed cost. Households 
determine which members work and the duration of their work. A shock to the marginal efficiency of investment causes an increase in the intensive margin of employed agents through the usual mechanism. However, it also causes an increase in the extensive margin (share of total agents in employment) as it becomes worthwhile for non-employed agents to pay the fixed cost and enter into market production. Compositional effects arising from the increase in the employment rate leads to a substantial increase in aggregate consumption which generates positive comovement.

Ascari, et al (2016) employ a medium-scale New Keynesian model with the addition of intermediate goods in the production function to resolve the comvement problem and (what they refer to as) the "Barro-King Curse". Their 'roundabout production' approach creates an amplification mechanism whereby an increase in output raises the use of intermediate inputs and further boosts output. This enables the possibility of positive correlation between consumption and investment with respect to MEI shocks. Furthermore, they demonstrate that TFP shocks do not always generate the expected unconditional positive correlation between output and hours, as implied by Barro and King (1984). This is due to substantial intratemporal substitution combined with the aforementioned amplification mechanism which causes a fall in hours on impact of a TFP shock.

Chen and Liao (2018) address the comovement problem utilising sticky-prices in a two-sector model with consumer durables. An investment shock increases the demand for new capital goods and raises the price of consumer durables relative to non-durables. The intra-temporal substitution away from durable consumption towards non-durable consumption dominates the intertemporal substitution effect whereby current non-durable consumption is reduced in order to fund new investments. As a result, non-durable consumption rises and positive comovement is achieved. However, whether intra-temporal substitutions dominates over intertemporal substitution is primarily governed by the elasticity of substitution between durables and non-durables. Sufficient complementarity is required to achieve the desired result - an elasticity of substitution just a little below unity, with benchmark parameter values, does not generate the appropriate comovement between consumption and investment.

Choi (2020) resolves the comovement problem in a standard neoclassical model which features time inconsistent agents who engaged in naive hyperbolic discounting. These naive agents tend 
towards immediate gratification and therefore weight present consumption more heavily than typical agents with rational expectations. This naturally causes naive agents to only moderately postpone leisure in response to MEI shocks and instead increases the correlation between output and consumption relative to a benchmark RBC model. Moreover, the inclusion of capital adjustment costs reduces the immediate response investment and consumption rises in response to a positive investment shock. This mechanism functions in a similar way to rule-of-thumb consumers by Furlanetto, et al (2013).

\section{Model Setup}

The infinitely lived representative agent exhibits KPR preferences and derives utility from consumption $C_{t}$ and disutility from work $L_{t}$ each period. Where $\beta \in(0,1)$ is the subjective discount factor, $\eta>0$ is the inverse Frisch elasticity, and $\chi>0$ is a scaling constant. The agent maximises discounted lifetime utility subject to the following constraints. ${ }^{2}$

$$
\begin{array}{r}
\sum_{t=0}^{\infty} \beta^{t}\left[\ln C_{t}-\chi \frac{L_{t}^{1+\eta}}{1+\eta}\right] \\
\text { s.t. }\left\{\begin{array}{l}
w_{t} L_{t}+r_{t} K_{t-1}=C_{t}+I_{t}+\Phi \\
K_{t}=(1-\delta) K_{t-1}+I_{t} X_{t} \\
\Phi=w_{t} L_{t} \tau_{t}
\end{array}\right.
\end{array}
$$

Where $\delta \in(0,1)$ represent the rate of capital depreciation and $\Phi \geq 0$ represents a fixed cost levied on labour each period. As $\Phi$ is constant, when hours worked increase, the labour wedge must immediately fall to satisfy the constraint above. This implies a negative contemporaneous relationship between labour (and therefore output) and the tax wedge $\tau_{t}$. The first order conditions follow as standard:

$$
\chi L_{t}^{\eta} C_{t}=w_{t}\left(1-\tau_{t}\right)
$$

\footnotetext{
${ }^{2}$ Capital stock is written as $K_{t-1}$ to emphasise that it is a state variable - this notation becomes useful for interpretation in in section 4.
} 


$$
\frac{C_{t+1}}{C_{t}}=\beta\left(X_{t} r_{t+1}+(1-\delta) \frac{X_{t}}{X_{t+1}}\right)
$$

Additionally, $\widetilde{w}_{t}$ can written to represent the post-tax wedge wage (not chosen directly by the agent):

$$
\widetilde{w}_{t}=w_{t}\left(1-\tau_{t}\right)
$$

To ensure all endogenous variables move optimally over the business cycle to meet the fixed cost $\Phi$, an auxiliary maximisation problem is required. ${ }^{3}$. Combining equations (1) and (3) with the initial constraints of the agent yield the central planner's constraints, shown below on the multipliers $\lambda_{t}, \theta_{t}, \mu_{t}$. The central planner then maximises welfare by choosing $C_{t}, L_{t}, \widetilde{w}_{t}$.

$$
\begin{gathered}
\mathcal{L}=\sum_{t=0}^{\infty} \beta^{t}\left[\ln C_{t}-\chi \frac{L_{t}^{1+\eta}}{1+\eta}\right] \\
+\lambda_{t}\left[w_{t} L_{t}-\widetilde{w}_{t} L_{t}-\Phi\right] \\
+\theta_{t}\left[\widetilde{w}_{t} L_{t}+r_{t} K_{t-1}+\frac{(1-\delta) K_{t-1}}{X_{t}}-\frac{K_{t}}{X_{t}}-C_{t}\right] \\
+\mu_{t}\left[\chi L_{t}^{\eta} C_{t}-\widetilde{w}_{t}\right]
\end{gathered}
$$

The first order conditions of the auxiliary maximisation problem are as follows, where equations (4) and (5) ensure that optimal intra-temporal decisions of the agent are respected and equation (6) indirectly determines the equilibrium path of the labour tax wedge $\tau_{t}$.

$$
\begin{gathered}
\mathcal{L}_{C}=\frac{1}{C_{t}}-\theta_{t}+\mu_{t} \chi L_{t}^{\eta}=0 \\
\mathcal{L}_{L}=-\chi L_{t}^{\eta}+\lambda_{t}\left(w_{t}-\widetilde{w}_{t}\right)+\theta_{t} \widetilde{w}_{t}+\mu_{t} \chi \eta L_{t}^{\eta-1} C_{t}=0 \\
\mathcal{L}_{\widetilde{w}}=-\lambda_{t} L_{t}+\theta_{t} L_{t}-\mu_{t}=0
\end{gathered}
$$

Equations (1) through (6) creates an endogenous labour wedge mechanism which operates counter-cyclically and amplifies the labour supply decision of the agent (analogous to an optimal labour tax). This transmission mechanism allows the model to remain tractable such that analytical expressions for comovement can be derived. Moreover, this simple mechanism captures two

\footnotetext{
${ }^{3}$ This setup is identical to the primal approach to optimal taxation; see Chamley (1986) or Ljungqvist and Sargent (2018)
} 
key observable features of the US labour market; a counter-cyclical labour wedge (Atesagaoglu and Elgin, 2014; Zhang, 2018) and improved fit in the volatility of hours worked. Furthermore, the representative firm faces Cobb-Douglas production technology and operates in a perfectly competitive market.

$$
Y_{t}=K_{t-1}^{\alpha} L_{t}^{1-\alpha}
$$

Firms maximise profit by hiring capital and labour. The first order conditions follow trivially:

$$
\begin{gathered}
r_{t}=\alpha \frac{Y_{t}}{K_{t-1}} \\
w_{t}=(1-\alpha) \frac{Y_{t}}{L_{t}}
\end{gathered}
$$

The model is closed with the autoregressive process where $\rho \in(0,1)$ is persistence of the shock, and where $\varepsilon_{t} \sim\left(0, \sigma^{\varepsilon}\right)$ is the zero mean shock process and $X_{t}$ represents MEI:

$$
\ln \left(X_{t}\right)=\rho \ln \left(X_{t-1}\right)+\varepsilon_{t}^{x}
$$

The equilibrium conditions (1) through (10), alongside additional constraints of the agent, are summarised in Table A1. Moreover, through algebraic manipulation closed-form expressions for steady state values (denoted with the subscript ss) are detailed in Table A2. The model is log-linearised and simulated with Dynare (linear equilibrium conditions are detailed in Table A3).

Eliminating redundant and static variables, the model can be represented in a state space formulation, where variables marked with ^ denote percentage deviations from the steady state. The Blanchard and Kahn (1980) method is used to solve the system of first-order linear difference equations. An equilibrium solution consists of a set of linear policy functions $\mathbb{P}_{t}=\mathbb{P}\left(K_{t-1}, X_{t-1}\right)$ for $\mathbb{P}_{t}=\left\{C_{t}, K_{t}, X_{t}\right\}$ such that the set of linear equilibrium equations are satisfied. These decision rules describe the path of the endogenous variables as a function of state variables and exogenous shocks. The set of decision rules contained within $\mathbb{P}_{t}$ are detailed as follows (derived in section A4): 


$$
\begin{gathered}
\hat{C}_{t}=\gamma_{k}^{c} \hat{K}_{t-1}+\gamma_{x}^{c} \hat{X}_{t-1}+\gamma_{\varepsilon}^{c} \varepsilon_{t} \\
\hat{K}_{t}=\gamma_{k}^{k} \hat{K}_{t-1}+\gamma_{x}^{k} \hat{X}_{t-1}+\gamma_{\varepsilon}^{k} \varepsilon_{t} \\
\hat{X}_{t}=\underbrace{\gamma_{k}^{x}}_{=0} \hat{K}_{t-1}+\underbrace{\gamma_{x}^{x}}_{=\rho} \hat{X}_{t-1}+\underbrace{\gamma_{\varepsilon}^{x}}_{=1} \varepsilon_{t}
\end{gathered}
$$

The coefficients $\gamma_{a}^{b}=f(\alpha, \beta, \delta, \phi, \eta, \rho)$ represent the partial elasticities of the superscript $(b)$ with respect to the subscript (a). Equipped with these decision rules above, the subset of the parameter space for which the comovement is achieved can be solved, this is detailed analytically and graphically below.

\section{Theoretical Result}

Suppose a steady state $t=s s$ exist and assume a small perturbation from equilibrium $t=s s+1$, in response to a positive MEI shock. For the comovement problem to be resolved, consumption and investment must increase on impact; this implies that (12.1) through (12.4) hold:

$$
\frac{d \hat{C}_{s s+1}}{d \varepsilon_{s s+1}} \geq 0 \quad(12.1), \quad \frac{d \hat{L}_{s s+1}}{d \varepsilon_{s s+1}} \geq 0 \quad(12.2), \quad \frac{d \hat{Y}_{s s+1}}{d \varepsilon_{s s+1}} \geq 0 \quad(12.3), \quad \frac{d \hat{I}_{s s+1}}{d \varepsilon_{s s+1}} \geq 0
$$

As both (12.3) and (12.4) are direct corollaries of (12.1) and (12.2), proof of (12.1) and (12.2) alone are sufficient to constitute a resolution to this puzzle (formal proofs for are confined to the appendix). The intuition is as follows: investment shocks appear only in the capital law of motion. Capital is a state variable and therefore, it is fixed in the current period. Subsequently, MEI shocks are not capable of impacting the existing capital stock immediately (one period must pass for before higher investment is carried over into increased capital stock). As a result, it is only possible to increase output (and thus allow consumption and investment to rise together) in the period of the shock by increasing labour input.

Setting $t=s s+1$ and differentiating the policy function for consumption (11.1) with respect to the MEI shock gives: 


$$
\frac{d \hat{C}_{s s+1}}{d \varepsilon_{s s+1}}=\gamma_{\varepsilon}^{c} \geq 0
$$

Imposing positivity on (13) and solving analytically gives the following expression (where $\phi=$ $\Phi / Y$ is the ratio of the fixed cost to steady state output):

$$
0 \geq \frac{(1-\alpha)(\alpha+\eta)-(1+\eta) \phi}{(1+\eta)}
$$

Moreover, via consolidation of the linear equilibrium conditions in table A3, labour can be expressed exclusively in terms of jump and state variables. Differentiating this yields a one-to-one mapping consumption to labour (in deviations from the steady state) in the period the MEI shock hits: ${ }^{4}$

$$
\frac{d \hat{L}_{s s+1}}{d \hat{C}_{s s+1}}=\frac{(1-\alpha-\phi)}{\phi(1-\alpha)-(\alpha+\eta)(1-\alpha-\phi)}
$$

Applying the chain rule using (13) and (15) solves for condition (12.2) and gives the following analytical expression:

$$
0 \leq \frac{(1-\alpha-\phi) \gamma_{\varepsilon}^{c}}{\phi(1-\alpha)-(\alpha+\eta)(1-\alpha-\phi)}
$$

If the set of parameter values satisfy (14) and (16), and the Blanchard-Kahn stability conditions hold, consumption and investment will both increase on impact in response to an MEI shock. Setting (14) (shown in red) and (16) (shown in blue) to zero gives the boundary conditions which allow for a convenient graphical representation of the main theoretical result - figure 4 plots the parameter subspace in terms of $\phi$ and $\delta$.

\footnotetext{
${ }^{4}$ Evidently, this expression only holds in the period of the shock. For $t>s s+1$ onward state variables are no longer fixed at its equilibrium value.
} 


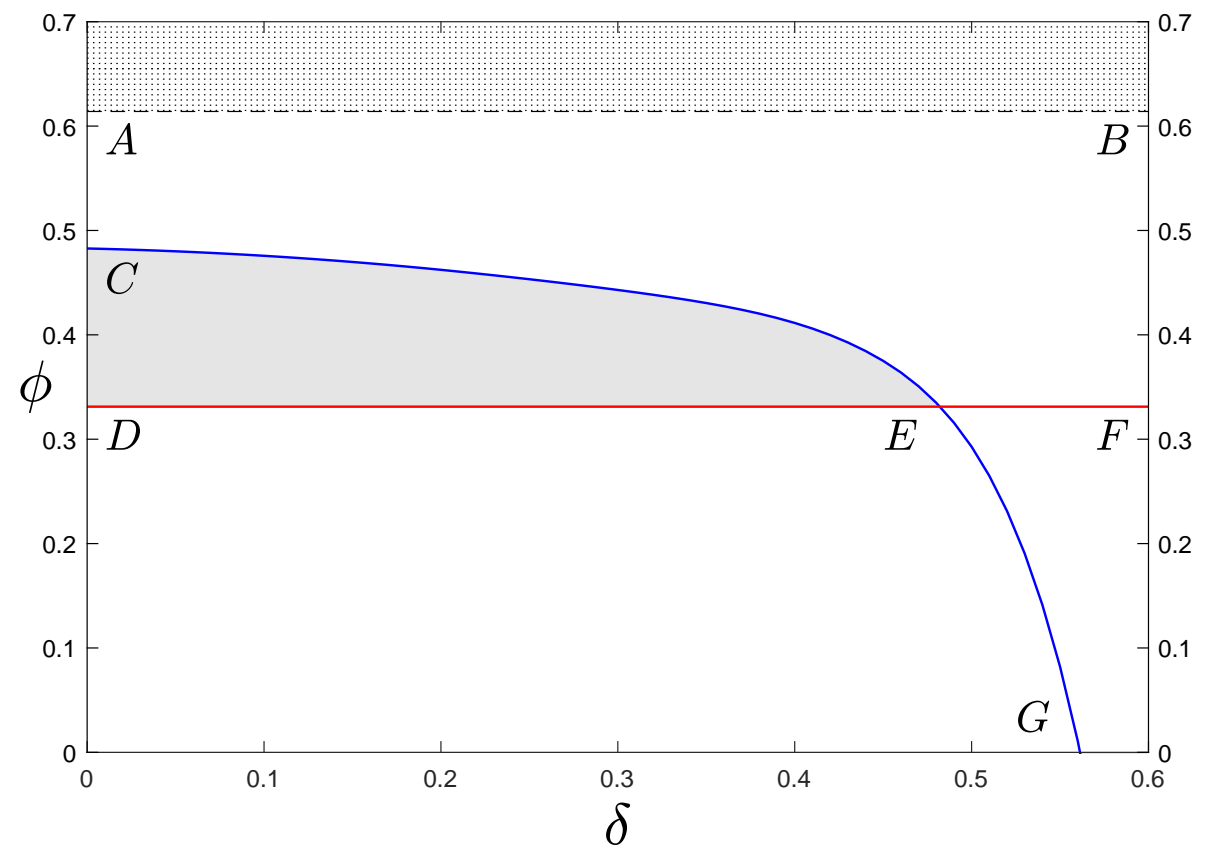

Figure 4: Parameter Subspace for Solving the Comovement Problem

Using calibrated parameter values (priors for estimated parameters) from section 5, the area above the dashed line AB represents the section of the parameter subspace $\delta$ - $\phi$ where no steady state exists. The fixed cost levied on labour cannot exceed the labour share of income, as it would imply that workers receive a negative post-tax wedge wage. All prices and quantities must be non-negative, thus the area above $\mathrm{AB}$ is ruled out. The square ABDF represents the region in which consumption and leisure are substitutes; in this region, consumption and labour will always move in the same direction in response to a perturbation from equilibrium. The area below the blue line CG represents the region in which labour increases on impact with respect to an MEI shock, in accordance with (16).

Therefore, to achieve positive comovement, the choice of parameters values must fall inside the grey shaded triangle CDE. Moreover, it can be seen that for some values of $\delta$ (beyond point E) it is not possible to generate positive comovement. This is because if $\delta$ is too large it thwarts the intratemporal substitution channel towards labour, as the marginal gain from investment is strictly decreasing with respect to capital depreciation. This theoretical result will aid the estimation procedure by guiding the prior choice of $\Phi=\phi Y$ such that it generates comovement. 


\section{Calibration and Estimation}

The model is estimated for annual US data from 1970-2019 via a combination of calibration and estimation; using series for consumption and capital stock. Consumption is defined as the sum of personal consumption expenditures on non-durable goods and services and capital stock is defined as the sum of non-residential fixed assets and consumer durable goods. The series are expressed in real per capita terms by using the GDP deflator and dividing by the civilian non-institutional population between 16 and 65. To ensure consistency with the stationary form of the model the series are de-trended with the HP filter (with a smoothing parameter of 100 for annual data).

Calibration: Parameters which have a clear interpretation and are directly observable from the steady state of the model are calibrated. Since $\alpha, \beta$ and $\delta$ are conceptually well-identified in this sense, they are calculated as follows. The capital share of income $\alpha$ is obtained from the inverse of the labour share (taken from the FRED database via Penn World Table). Equation (2) in the steady state gives the expression which pins down the discount factor $\beta=1 /(1+r)$, given the risk-free real interest rate $r=i-\pi$. This is calculated by taking the average of the nominal 10-year T-bill rate $i$ and subtracting the average rate of inflation $\pi$ for the same period implied by the GDP deflator. Capital depreciation $\delta$ is calibrated using the equilibrium expression from the capital law of motion. This corresponds to $\delta=I / K$, where $K$ refers to capital stock as previously defined and $I$ refers to non-residential fixed investment plus expenditure on consumer durable goods (from the NIPA Tables produced by the BEA).

Table 1: Calibrated Parameters

\begin{tabular}{|c|c|c|}
\hline Parameter & Description & Value \\
\hline$\alpha$ & Capital Share & 0.386 \\
\hline$\beta$ & Discount Factor & 0.972 \\
\hline$\delta$ & Depreciation Rate & 0.139 \\
\hline
\end{tabular}


Estimation: All remaining parameters are estimated. The prior mean for the inverse Frisch elasticity is taken as from the literature, reflecting estimates of $1 / \eta$ between 2 and 4 (see Peterman, 2016 and Chetty, 2012). The aforementioned series are used in the estimation process, therefore, along with the MEI shock, a further shock is added; a total factor productivity shock (TFP) shock. The prior mean for the persistence parameter of the MEI shock is obtained through de-trending the relative price of investment goods (a proxy for the marginal efficiency of investment). A standard auto-regression is then run to determine the persistence parameter. The same procedure is applied to the total factor productivity residual (from FRED database via the Penn World Table) to obtain a prior mean for the persistence parameter of the TFP shock. Exogenous shock standard deviation values are chosen in line with those existing in the literature (see Kahn and Tsokuas, 2011 and..).

Model Informed Parameters: One final parameter needs to be estimated, namely, the fixed labour cost $\Phi$. Instead of being informed directly by the data, the choice of priors here is informed by expressions derived from the model itself. Using (14) and (16) and the calibrated parameters in Figure 1, lower and upper bound values for $\Phi$ consistent with positive comovement can be inferred. This is illustrated with an application of Figure 4. 


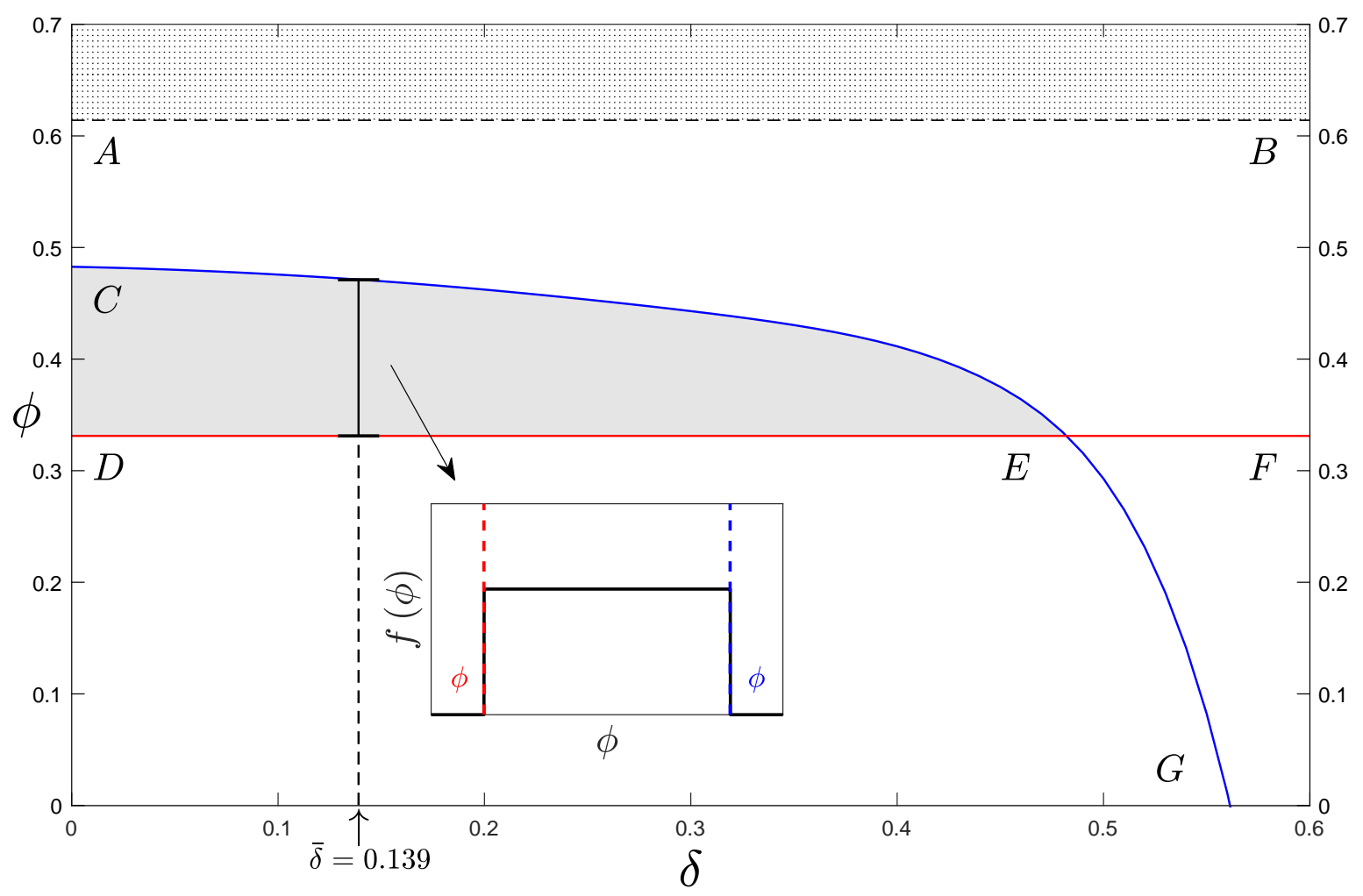

Figure 5: Parameter Subspace for Solving the Comovement Problem

The grey area CDE represents the subset of the parameter space which generates positive comovement. Since $\delta$ is known through calibration, the area of interest can be restricted to the solid black line which spans the area CDE. The top part of the triangle (the blue line CG) serves as the upper bound value while the bottom part of the triangle (the flat red line DF) serves as the lower bound value. A uniform distribution is then chosen for $\Phi$, as denoted in the subplot inside Figure 5. As the distribution is uniform, the prior mean and standard deviation for $\Phi$ can be inferred. Imposing these bounds restricts the parameter space during the estimation process such that positive comovement in response to an MEI shock is guaranteed. The estimated parameters are detailed in table 2 below:

Table 2: Estimated Parameters 


\begin{tabular}{|c|c|c|c|c|c|c|c|c|}
\hline \multirow[t]{2}{*}{ 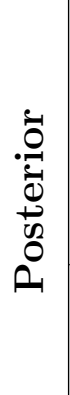 } & 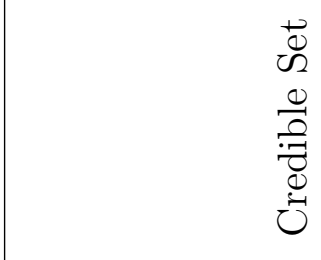 & 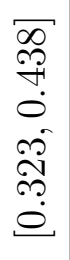 & $\begin{array}{l}\overline{\mathscr{D}} \\
\stackrel{N}{0} \\
0 \\
+\mathfrak{N} \\
0 \\
0\end{array}$ & 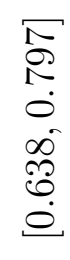 & $\begin{array}{l}\mathbb{N} \\
\dot{O} \\
0 \\
0 \\
0 \\
0 \\
0 \\
0\end{array}$ & $\begin{array}{l}0 \\
0 \\
0 \\
0 \\
1 \\
0 \\
0 \\
0 \\
0\end{array}$ & 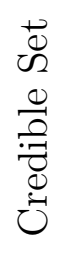 & 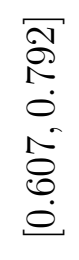 \\
\hline & $\sum_{\Sigma}^{\mathbb{E}}$ & $\underset{\substack{+0}}{\stackrel{+}{0}}$ & $\begin{array}{l}\infty \\
\stackrel{2}{?} \\
0\end{array}$ & 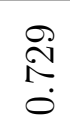 & 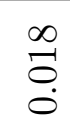 & $\stackrel{\infty}{8}$ & 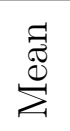 & $\begin{array}{l}\infty \\
\stackrel{0}{0} \\
\stackrel{0}{0}\end{array}$ \\
\hline \multirow{2}{*}{ 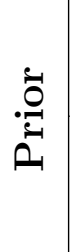 } & 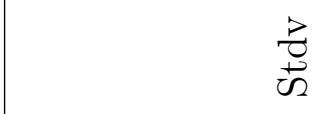 & $\stackrel{20}{0}$ & $\stackrel{20}{0}$ & $\stackrel{20}{0}$ & $\underset{-}{\stackrel{8}{-}}$ & $\underset{-}{\stackrel{8}{-}}$ & $\stackrel{m}{p}$ & $\begin{array}{l}2 \\
2 \\
0 \\
0\end{array}$ \\
\hline & 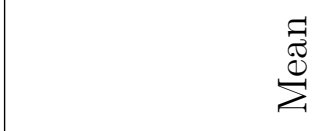 & 总 & $\begin{array}{l}\mathscr{O} \\
\tilde{\sigma} \\
0\end{array}$ & $\begin{array}{l}\vec{D} \\
\dot{0} \\
0\end{array}$ & 号 & $\begin{array}{l}0 \\
0 \\
0 \\
0\end{array}$ & $\stackrel{\oplus}{\oplus}$ & 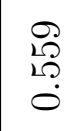 \\
\hline 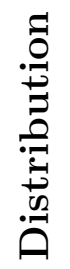 & \multirow{3}{*}{ рәшлојиі еұе } & 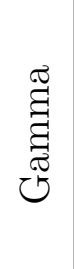 & $\stackrel{\substack{0 \\
0}}{0}$ & $\underset{0}{\frac{\pi}{0}}$ & 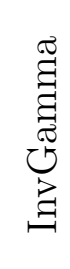 & 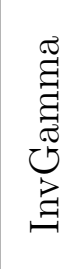 & \multirow{3}{*}{ 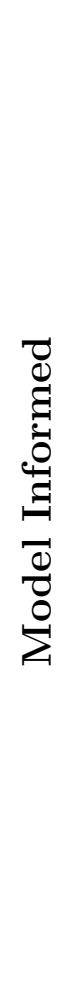 } & 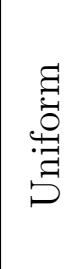 \\
\hline 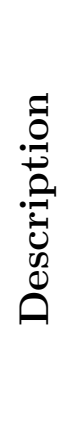 & & 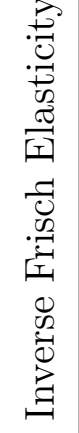 & 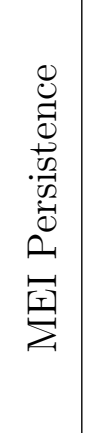 & 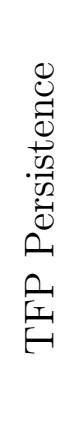 & 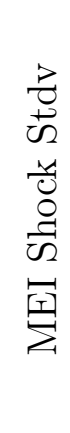 & 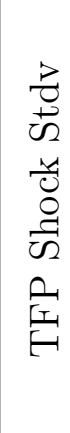 & & ש \\
\hline 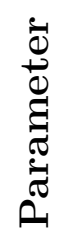 & & $=$ & 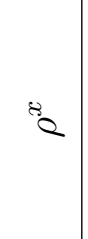 & $\stackrel{8}{e}$ & 0 & io & & $\theta$ \\
\hline
\end{tabular}

The estimation procedure is performed via Dynare and the parameter posteriors are obtained via the Metropolis-Hastings algorithm using 20,000 draws, with the first 5,000 draws discarded. The model is then simulated using the posterior distributions. The Bayesian IRFs shown below correspond to the mean impulse responses for a one percent shock to the marginal efficiency of investment. The solid line corresponds to the model where $\Phi=0.698$ while the dashed line corresponds to $\Phi=0$ (nested standard RBC model with calibrated parameters from Table 1 and estimated parameters shown in Table A4). 

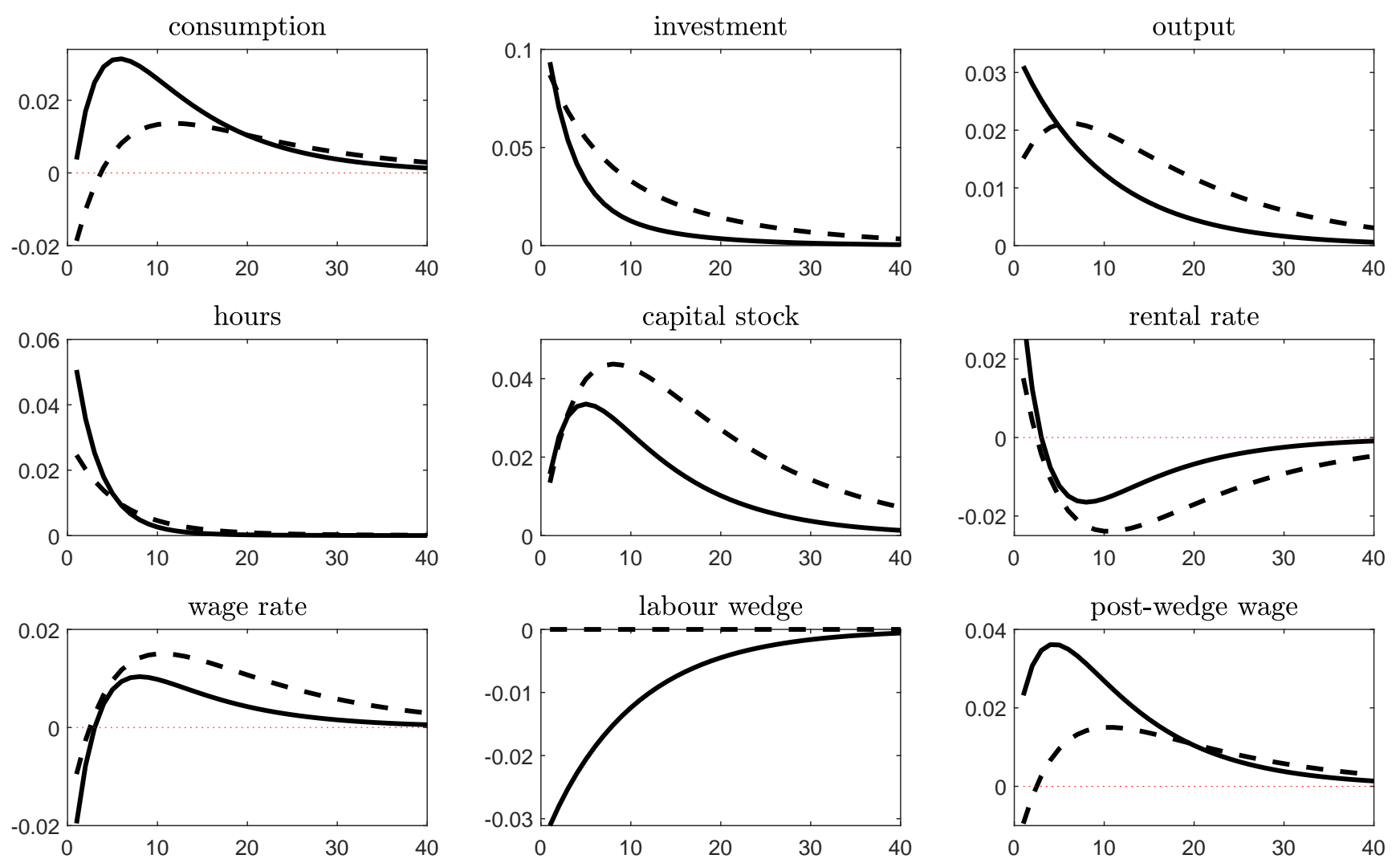

Figure 6: MEI Shock Bayesian (median) IRFs (solid line $\Phi=0.698$ dashed line $\Phi=0$ )

Impulse Response Functions: As shown in Figure 6, an MEI shock directly causes the interest rate to rise on impact as the relative price of investment falls. Due to inter-temproral substitution, future consumption becomes more attractive relative to present consumption and investment increases significantly. This occurs under both specifications of the model, reflected in the similar impulse responses for the solid and dashed lines for investment and the rental rate.

However, intra-temporal substitution is more pronounced under the labour wedge specification, relative to the benchmark model. As leisure is foregone, the solid line for the response of the wage rate (labour productivity) falls more than the dashed line. By postponing leisure, the labour wedge falls by definition, as the fixed cost on labour remains unchanged. This creates an amplification mechanism whereby the post-tax wedge wage rises on impact and incentivises workers to supply more labour.

This is reflected by solid line in the stronger response of hours worked, which then sharply returns to its steady state level. Additional intra-temporal substitution further boosts output under the labour wedge specification. This can be seen in the stronger (monotonic) response of 
output on impact in the solid line, compared with the weaker (hump-shaped) response of output by the dashed line. Ultimately, the additional increase in output (relative to the benchmark $\mathrm{RBC}$ ) provides the necessary slack in the resource constraint such that consumption rises upon impact and exhibits comovement with output, investment, and hours - replicating the unconditional correlations observed in the data.

This is due to the presence of the counter-cyclical labour wedge which amplifies the intratemporal substitution in the short run and generates a stronger response for consumption. Moreover, notably, in the impulse response for consumption, the highest posterior density intervals is fully contained within the positive region (figure 8 appendix) indicating that the model comprehensively generates a positive response on impact (as expected from the parameter restriction imposed on $\Phi)$.

Historical Shock Decomposition: Figure 7 and 8 displays the shock decomposition for the observable series for the laboue wedge setup and benchmark RBC specifications, respectively. Moreover, Table 4 also details the posterior mean variance decomposition for each shock for all the key endogenous variables. In figure 7, the labour wedge specification it can be seen that the labour wedge specification increases the role played by investment shocks. This is because the intra-temporal substitution mechanism amplies the propogation of investment shocks. Naturally, under both specifications, fluctuations in capital stock are more strongly impacted by investment shocks. Whereas under the labour wedge specification investment shocks account for over half of the historic flucutations in consumption, but under the benchmark RBC specification account for just under one-tenth of historic fluctuations. Put simpy, when the labour wedge mechanism is shutdown TFP shocks play a much greater role in driving business cycles. 

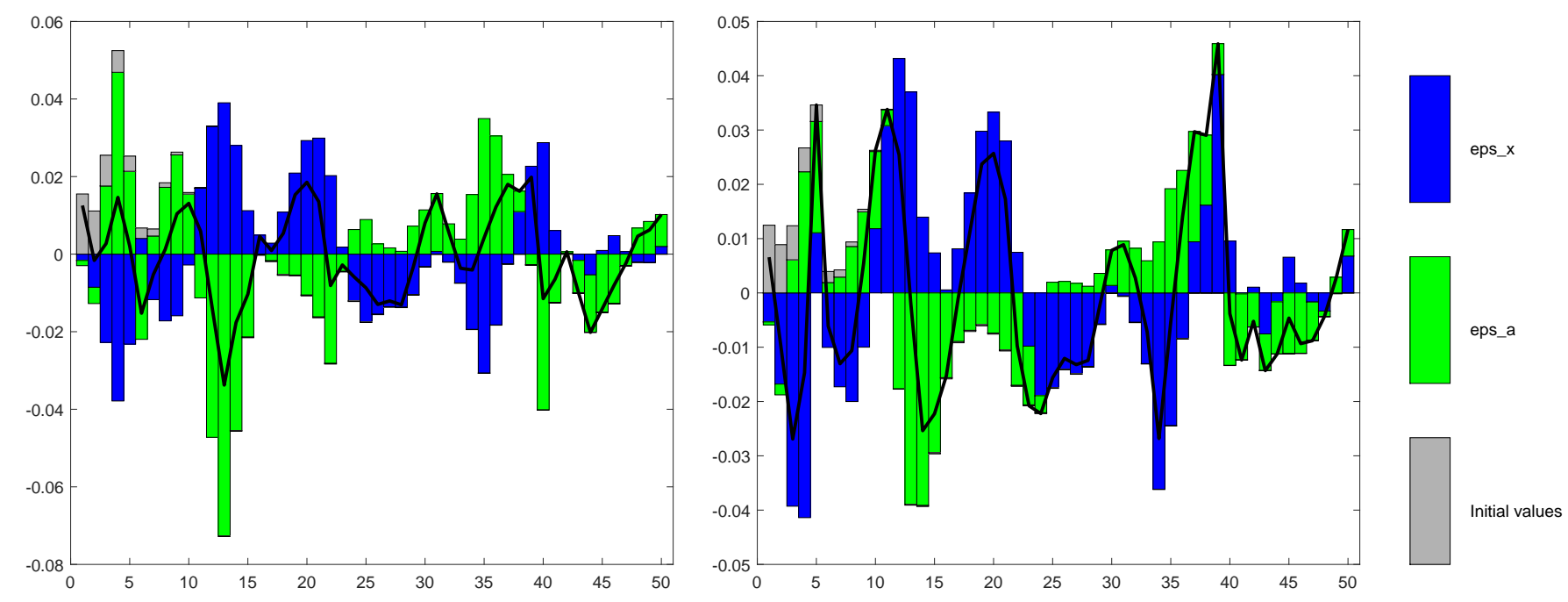

Figure 7: Consumption (left) and Capital (right) - labour wedge setup $\Phi=0.698$
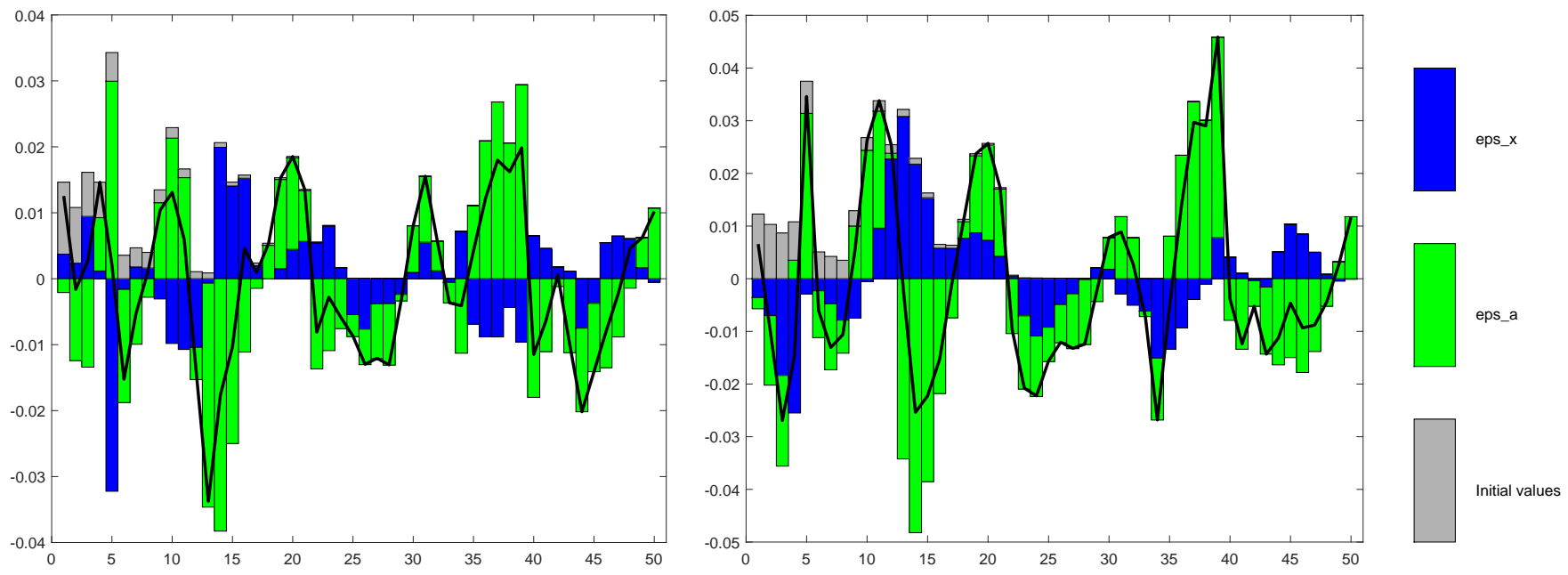

Figure 8: Consumption (left) and Capital (right) - benchmark RBC $\Phi=0$

Non-observed key variables can be inferred from the estimation procedure, their shock decomposition (series constructed during estimation) is detailed below in table 4 for both specifications of the model.

Table 4: Posterior Mean Variance Decomposition 


\begin{tabular}{|c|c|c|c|c|}
\hline Specification & \multicolumn{2}{|c|}{ Labour Wedge Setup } & \multicolumn{2}{c|}{ Benchmark RBC } \\
\hline Variable & MEI Shocks & TFP Shocks & MEI Shocks & TFP Shocks \\
\hline Consumption & $66.47 \%$ & $33.53 \%$ & $9.85 \%$ & $90.15 \%$ \\
\hline Investment & $71.04 \%$ & $28.96 \%$ & $11.57 \%$ & $88.43 \%$ \\
\hline Output & $66.51 \%$ & $33.49 \%$ & $4.18 \%$ & $95.82 \%$ \\
\hline Hours & $74.28 \%$ & $25.72 \%$ & $21.30 \%$ & $78.7 \%$ \\
\hline Capital & $76.16 \%$ & $23.84 \%$ & $17.57 \%$ & $82.43 \%$ \\
\hline Rental Rate & $71.95 \%$ & $28.05 \%$ & $11.46 \%$ & $88.43 \%$ \\
\hline Wage Rate & $77.18 \%$ & $22.82 \%$ & $6.13 \%$ & $93.87 \%$ \\
\hline
\end{tabular}

It can be seen that under the labour wedge setup that MEI shocks are a significant driver of business cycle fluctuations - accounting for two-thirds of the fluctuations in output and consumption. Under the benchmark RBC specification, less than $10 \%$ of the fluctuations in output and consumption are attributed to investment shocks. A similar pattern is exhibited for hours worked, under the RBC specification TFP shocks are the overwhelming driver of fluctuations in hours worked, for the labour wedge specification, it is reversed and MEI shocks are the main driver.

Moreover, the fit of the two specifications can be compared by the log marginal likelihood. The estimation procedure indicates that the labour wedge specification (lws) $\ln \left(p\left(C_{t}, K_{t}\right) \mid \mathcal{M}_{L W S}\right)=$ -272.21 exhibits a larger value for the log data density than the benchmark RBC specification (rbc) $\ln \left(p\left(C_{t}, K_{t}\right) \mid \mathcal{M}_{R B C}\right)=-290.79$. This indicates Bayes factor which favours the fit of the labour wedge setup for the data.

\section{Conclusion}

Shocks to the marginal efficiency of investment play a significant role in business cycle fluctuations. However, in typical structural models, these shocks cause consumption to fall on impact while investment rises. This conflicts with well-established observations which show that both consumption and investment move together over the business cycle. This puzzle can be accounted for by the relative weakness of the intra-temporal substitution channel in response to MEI shocks. 
This paper proposes a resolution to this problem through the inclusion of a time-varying labour wedge into a standard RBC framework. The implications are four-fold. 1) The labour wedge specification comfortably generates the unconditional correlations observed in the data for an empirically reasonable set of parameter values; consumption rises in response to MEI shocks and exhibits comovement with output, investment, and hours worked. 2) This straightforward setup permits tractable analytical expressions which describe the subset of the parameter space where positive comovement is achieved. 3) Estimation indicates that model fit of the labour wedge specification is superior to the benchmark RBC specification. 4) The shock decomposition generates findings in line with the recent literature with regards to the importance of investment shocks as being key drivers of business cycle fluctuations. Based on these findings it can be concluded that intra-temporal substitution generated by the labour wedge plays a crucial role in understanding the propagation of MEI shocks and being able to replicate observed business cycle data in a parsimonious way. 


\section{Appendix}

This appendix covers the details of the model derivation and the theoretical results contained in the main body of the paper. It is structured as follows: the first part details the model and its steady states, the second part derives the consumption policy function analytically from the linear model and the boundary conditions required for comovement, and the third section details some additional proofs for completeness.

\section{A. Model Details}

Table A1: Model Equations

\begin{tabular}{|c|c|}
\hline Labour Supply & $\chi L_{t}^{\eta} C_{t}=w_{t}\left(1-\tau_{t}\right)$ \\
\hline Capital Supply & $\frac{C_{t+1}}{C_{t}}=\beta\left(X_{t} r_{t+1}+(1-\delta) \frac{X_{t}}{X_{t+1}}\right)$ \\
\hline Labour Demand & $w_{t}=(1-\alpha) \frac{Y_{t}}{L_{t}}$ \\
\hline Capital Demand & $r_{t}=\alpha \frac{Y_{t}}{K_{t-1}}$ \\
\hline Production Function & $Y_{t}=A_{t} K_{t-1}^{\alpha} L_{t}^{1-\alpha}$ \\
\hline Accounting Identity & $Y_{t}=C_{t}+I_{t}+\Phi$ \\
\hline Law of Motion & $K_{t}=(1-\delta) K_{t-1}+I_{t} X_{t}$ \\
\hline Post-Tax Wage Rate & $w_{t}\left(1-\tau_{t}\right)=\widetilde{w}_{t}$ \\
\hline Fixed Labour Cost & $\Phi=w_{t} L_{t} \tau_{t}$ \\
\hline Consumption Optimality & $\frac{1}{C_{t}}-\theta_{t}+\mu_{t} \chi L_{t}^{\eta}=0$ \\
\hline Labour Optimality & $-\chi L_{t}^{\eta}+\lambda_{t}\left(w_{t}-\widetilde{w}_{t}\right)+\theta_{t} \widetilde{w}_{t}+\mu_{t} \chi \eta L_{t}^{\eta-1} C_{t}=0$ \\
\hline Tax Wedge Optimality & $-\lambda_{t} L_{t}+\theta_{t} L_{t}-\mu_{t}=0$ \\
\hline MEI Persistence & $\ln X_{t}=\rho_{x} \ln X_{t-1}+\varepsilon_{t}^{x}$ \\
\hline TFP Persistence & $\ln A_{t}=\rho_{a} \ln A_{t-1}+\varepsilon_{t}^{a}$ \\
\hline
\end{tabular}

Through algebraic manipulation closed-form expressions for steady state values can be obtained (time subcripts are dropped to denote steady state values). For simplicity, the marginal efficiency of investment, total factor productivity and labour input are all normalised to unity in the steady 
state. $^{5}$

Table A2: Steady State Expressions

\begin{tabular}{|c|c|}
\hline \multicolumn{2}{|c|}{ Endogenous Variables } \\
\hline Rental Rate & $r=\frac{1-\beta+\beta \delta}{\beta}$ \\
\hline Capital Stock & $K=\left(\frac{\alpha \beta}{1-\beta+\beta \delta}\right)^{\frac{1}{1-\alpha}}$ \\
\hline Investment & $I=\delta\left(\frac{\alpha \beta}{1-\beta+\beta \delta}\right)^{\frac{1}{1-\alpha}}$ \\
\hline Output & $Y=\left(\frac{\alpha \beta}{1-\beta+\beta \delta}\right)^{\frac{\alpha}{1-\alpha}}$ \\
\hline Consumption & $C=\left(\frac{\alpha \beta}{1-\beta+\beta \delta}\right)^{\frac{\alpha}{1-\alpha}}-\delta\left(\frac{\alpha \beta}{1-\beta+\beta \delta}\right)^{\frac{1}{1-\alpha}}-\Phi$ \\
\hline Marginal Product of Labour & $w=(1-\alpha)\left(\frac{\alpha \beta}{1-\beta+\beta \delta}\right)^{\frac{\alpha}{1-\alpha}}$ \\
\hline Wage Rate & $\widetilde{w}=(1-\alpha)\left(\frac{\alpha \beta}{1-\beta+\beta \delta}\right)^{\frac{\alpha}{1-\alpha}}-\Phi$ \\
\hline Labour Wedge & $\tau=\frac{\Phi}{(1-\alpha)}\left(\frac{1-\beta+\beta \delta}{\alpha \beta}\right)^{\frac{\alpha}{1-\alpha}}$ \\
\hline \multicolumn{2}{|c|}{ Costate Variables } \\
\hline Shadow Price of Intratemporal Optimality & $\mu=\frac{1-\frac{w}{\chi C}}{\Phi\left(1-\frac{1}{\chi}\right)+\widetilde{w}+\eta C}$ \\
\hline Shadow Price of Reducing the Excess Tax Burden & $\lambda=\frac{1}{C}-\mu(1-\chi)$ \\
\hline Shadow Price of Aggregate Wealth & $\theta=\mu+\lambda$ \\
\hline
\end{tabular}

Log-linearising the system of equations in Table A1 and making use of the steady state expressions in Table A2, the linear model can be expressed by the equations in A3:

Table A3: Linear Equilibrium Equations

${ }^{5}$ The value of the scaling constant which ensures this is $\chi=\frac{(1-\alpha)\left(\frac{\alpha \beta}{1-\beta+\beta \delta}\right)^{\frac{\alpha}{1-\alpha}}-\Phi}{\left(\frac{\alpha \beta}{1-\beta+\beta \delta}\right)^{\frac{\alpha}{1-\alpha}}-\delta\left(\frac{\alpha \beta}{1-\beta+\beta \delta}\right)^{\frac{1}{1-\alpha}}-\Phi}$ 


\begin{tabular}{|c|c|}
\hline Labour Supply & $\eta \hat{L}_{t}+\hat{C}_{t}=\hat{w}_{t}-\left(\frac{\tau}{1-\tau}\right) \hat{\tau}_{t}$ \\
\hline Capital Supply & $\hat{C}_{t+1}=\hat{C}_{t}+\hat{X}_{t}+r \beta \hat{r}_{t+1}-\beta(1-\delta) \hat{X}_{t+1}$ \\
\hline Labour Demand & $\hat{w}_{t}=\alpha \hat{K}_{t}-\alpha \hat{L}_{t}$ \\
\hline Capital Demand & $\hat{r}_{t}=-(1-\alpha) \hat{K}_{t}+(1-\alpha) \hat{L}_{t}$ \\
\hline Production Function & $\hat{Y}_{t}=\alpha \hat{K}_{t}+(1-\alpha) \hat{L}_{t}$ \\
\hline Accounting Identity & $\hat{Y}_{t}=\left(\frac{C}{Y}\right) \hat{C}_{t}+\left(\frac{I}{Y}\right) \hat{I}_{t}$ \\
\hline Law of Motion & $\hat{K}_{t+1}=(1-\delta) \hat{K}_{t}+\left(\frac{I}{K}\right) \hat{I}_{t}+\left(\frac{I}{K}\right) \hat{X}_{t}$ \\
\hline Net-Wage Rate & $\hat{\tilde{w}}_{t}=\hat{w}_{t}-\left(\frac{\tau}{1-\tau}\right) \hat{\tau}_{t}$ \\
\hline Fixed Labour Cost & $\hat{\tau}_{t}=-\hat{w}_{t}-\hat{L}_{t}$ \\
\hline Consumption Optimality & $\hat{C}_{t}=(C \mu \chi) \hat{\mu}_{t}-(C \theta) \hat{\theta}_{t}$ \\
\hline Labour Optimality & $\eta \hat{L}_{t}-\left(\frac{\eta \mu}{1-\eta \mu}\right) \hat{\mu}_{t}+\left(\frac{\eta \mu}{1-\eta \mu}\right) \hat{L}_{t}+\hat{C}_{t}=\hat{\lambda}_{t}+\left(\frac{w}{w-w}\right) \hat{w}_{t}+\hat{\tilde{w}}_{t}\left(1-\frac{\widetilde{w}}{w-w}\right)+\hat{\theta}_{t}$ \\
\hline Net-Wage Optimality & $\hat{\mu}_{t}=\left(\frac{\theta}{\mu}\right) \hat{\theta}_{t}-\left(\frac{\lambda}{\mu}\right) \hat{\lambda}_{t}+\left(\frac{\theta-\lambda}{\mu}\right) \hat{L}_{t}$ \\
\hline MEI Persistence & $\hat{X}_{t+1}=\rho_{x} \hat{X}_{t}+\varepsilon_{t+1}^{x}$ \\
\hline TFP Persistence & $\hat{A}_{t+1}=\rho_{a} \hat{A}_{t}+\varepsilon_{t+1}^{a}$ \\
\hline
\end{tabular}

\section{B. Derivation of Theoretical Results}

Solving for Eigenvalues: eliminating static/redundant variables, and using the short-hand notation $\varphi=1-\beta+\beta \delta$ and $\psi=1-\alpha-\phi$, the log-linear system of equations in Table A2 can be represented in state-space form as follows (with respect to MEI shocks only):

$$
\begin{gathered}
\vec{y}_{t+1}=M{\overrightarrow{y_{t}}}+\vec{z}_{t+1} \\
{\left[\begin{array}{c}
\hat{C}_{t+1} \\
\hat{K}_{t+1} \\
\hat{X}_{t+1}
\end{array}\right]=\left[\begin{array}{ccc}
\left(1+\frac{(1-\alpha) \varphi \psi}{\phi(1-\alpha)-(\alpha+\eta) \psi}\right) & (\alpha-1)\left(\varphi+\frac{\varphi \alpha(1-\alpha)}{\phi(1-\alpha)-(\alpha+\eta) \psi}\right) & (1-\beta(1-\delta) \rho) \\
\left(\frac{(1-\alpha) \varphi \psi}{\alpha \beta \phi(1-\alpha)-\alpha \beta(\alpha+\eta) \psi}-\frac{(1-\phi) \varphi}{\alpha \beta}+\delta\right) & \left(\frac{1}{\beta}-\frac{(1-\alpha) \varphi(1-\alpha)}{\alpha \beta \phi(1-\alpha)-\alpha \beta(\alpha+\eta) \psi}\right) & \delta \\
0 & 0 & \rho_{x}
\end{array}\right]\left[\begin{array}{c}
\hat{C}_{t} \\
\hat{K}_{t} \\
\hat{X}_{t}
\end{array}\right]+\left[\begin{array}{c}
0 \\
0 \\
\varepsilon_{t+1}^{x}
\end{array}\right]}
\end{gathered}
$$

Where $\overrightarrow{y_{t}}$ represents the vector of endogenous variables at time $t, M$ represents the Jacobian matrix and $\vec{z}_{t+1}$ is the shock vector. In order to derive the linear policy functions, the Eigenvalues $\lambda_{i}$ of the Jacobian must first be found for $i=1,2,3$. 


$$
D E T\left[\begin{array}{ccc}
\left(1+\frac{(1-\alpha) \varphi \psi}{\phi(1-\alpha)-(\alpha+\eta) \psi}\right)-\lambda_{i} & (\alpha-1)\left(\varphi+\frac{\varphi \alpha(1-\alpha)}{\phi(1-\alpha)-(\alpha+\eta) \psi}\right) & (1-\beta(1-\delta) \rho) \\
\left(\frac{(1-\alpha) \varphi \psi}{\alpha \beta \phi(1-\alpha)-\alpha \beta(\alpha+\eta) \psi}-\frac{(1-\phi) \varphi}{\alpha \beta}+\delta\right) & \left(\frac{1}{\beta}-\frac{(1-\alpha) \varphi \alpha(1-\alpha)}{\alpha \beta \phi(1-\alpha)-\alpha \beta(\alpha+\eta) \psi}\right)-\lambda_{i} & \delta \\
0 & 0 & \rho_{x}-\lambda_{i}
\end{array}\right]=0
$$

The characteristic (cubic) polynomial the Eigenvalues can be solved through factorisation and the quadratic formula as follows (where $\theta$ represents a constant). ${ }^{6}$ The closed-form expressions for the Eigenvalues are:

$$
\begin{gathered}
\lambda_{1}=\frac{\frac{(1-\alpha) \varphi(\alpha+\beta \psi-1)}{\phi \beta(1-\alpha)-\beta(\alpha+\eta) \psi}+\frac{1+\beta}{\beta}-\sqrt{\left(\frac{(1-\alpha) \varphi(\alpha+\beta \psi-1)}{\phi \beta(1-\alpha)-\beta(\alpha+\eta) \psi}+\frac{1+\beta}{\beta}\right)^{2}-4 \theta}}{2} \\
\lambda_{2}=\frac{\frac{(1-\alpha) \varphi(\alpha+\beta \psi-1)}{\phi \beta(1-\alpha)-\beta(\alpha+\eta) \psi}+\frac{1+\beta}{\beta}+\sqrt{\left(\frac{(1-\alpha) \varphi(\alpha+\beta \psi-1)}{\phi \beta(1-\alpha)-\beta(\alpha+\eta) \psi}+\frac{1+\beta}{\beta}\right)^{2}-4 \theta}}{2} \\
\lambda_{3}=\rho_{x}
\end{gathered}
$$

The Eigenvalues of $M$ can be represented in terms of the diagonal matrix $\Lambda$ :

$$
\Lambda=\left[\begin{array}{ccc}
\lambda_{1} & 0 & 0 \\
0 & \lambda_{2} & 0 \\
0 & 0 & \lambda_{3}
\end{array}\right]
$$

Solving for Eigenvectors: there are three Eigenvectors $\vec{v}_{i}=\left[\begin{array}{lll}\nu_{1 i} & \nu_{2 i} & \nu_{3 i}\end{array}\right]^{\prime}$ corresponding to the three distinct Eigenvalues $\lambda_{i}$ of the model. Recalling the definition of an Eigenvector:

$$
\begin{gathered}
M \vec{v}_{i}=\lambda_{i} \overrightarrow{v_{i}} \\
\left(M-\lambda_{i}\right) \vec{v}_{i}=0
\end{gathered}
$$

Solving for the Eigenvectors $\overrightarrow{v_{i}}$ and normalising each of the first elements to unity for $i=1,2,3$ (where $\vartheta=\frac{(1-\alpha) \varphi}{\phi(1-\alpha)-(\alpha+\eta) \psi}$ is shorthand) gives:

\footnotetext{
${ }^{6}$ The constant in the quadratic formula $\theta=\left(1+\frac{(1-\alpha) \varphi \psi}{\phi(1-\alpha)-(\alpha+\eta) \psi}\right)\left(\frac{1}{\beta}-\frac{(1-\alpha) \varphi \alpha(1-\alpha)}{\alpha \beta \phi(1-\alpha)-\alpha \beta(\alpha+\eta) \psi}\right)-$ $\left(\frac{(1-\alpha) \varphi \psi}{\alpha \beta \phi(1-\alpha)-\alpha \beta(\alpha+\eta) \psi}-\frac{(1-\phi) \varphi}{\alpha \beta}+\delta\right)\left(\varphi(\alpha-1)+\frac{(\alpha-1) \varphi \alpha(1-\alpha)}{\phi(1-\alpha)-(\alpha+\eta) \psi}\right)$
} 


$$
\begin{aligned}
& \overrightarrow{v_{1}}=\left[\begin{array}{c}
\nu_{11} \\
\nu_{21} \\
\nu_{31}
\end{array}\right]=\left[\begin{array}{c}
1 \\
\frac{1+\vartheta \psi-\lambda_{1}}{(1-\alpha)(\varphi+\vartheta \alpha)} \\
0
\end{array}\right] \\
& \overrightarrow{v_{2}}=\left[\begin{array}{c}
\nu_{12} \\
\nu_{22} \\
\nu_{32}
\end{array}\right]=\left[\begin{array}{c}
1 \\
\frac{1+\vartheta \psi-\lambda_{2}}{(1-\alpha)(\varphi+\vartheta \alpha)} \\
0
\end{array}\right] \\
& \overrightarrow{v_{3}}=\left[\begin{array}{c}
\nu_{13} \\
\nu_{23} \\
\nu_{33}
\end{array}\right]=\left[\begin{array}{c}
1 \\
\frac{\frac{\vartheta \psi-(1-\phi) \varphi}{\alpha \beta}+\delta \frac{\lambda_{3}-\vartheta \psi-\beta(1-\delta) \rho}{1-\beta(1-\delta) \rho}}{\frac{\delta(\alpha-1)((+\alpha))}{1-\beta(1-\delta) \rho}-\frac{1-\vartheta+\alpha \vartheta}{\beta}+\lambda_{3}} \\
\frac{\frac{\varphi-\phi \varphi-\vartheta \psi}{\delta \alpha}-\frac{\beta}{\varphi}-\frac{1-\vartheta+\vartheta \alpha-\beta \lambda_{3}}{\delta} \nu_{23}}{\beta}
\end{array}\right]
\end{aligned}
$$

The Eigenvectors can be stacked into a square matrix $V$ as follows:

$$
V=\left[\begin{array}{ccc}
\nu_{11} & \nu_{12} & \nu_{13} \\
\nu_{21} & \nu_{22} & \nu_{23} \\
\nu_{31} & \nu_{32} & \nu_{33}
\end{array}\right]
$$

Consumption Policy Function: By definition the Jacobian matrix can be expressed in terms of the diagonal matrix of Eigenvalues and the stacked matrix of Eigenvectors:

$$
\begin{gathered}
M V=V \Lambda \\
M=V \Lambda V^{-1} \\
M=\left[\begin{array}{lll}
\nu_{11} & \nu_{12} & \nu_{13} \\
\nu_{21} & \nu_{22} & \nu_{23} \\
\nu_{31} & \nu_{32} & \nu_{33}
\end{array}\right]\left[\begin{array}{ccc}
\lambda_{1} & 0 & 0 \\
0 & \lambda_{2} & 0 \\
0 & 0 & \lambda_{3}
\end{array}\right]\left[\begin{array}{lll}
\nu_{11} & \nu_{12} & \nu_{13} \\
\nu_{21} & \nu_{22} & \nu_{23} \\
\nu_{31} & \nu_{32} & \nu_{33}
\end{array}\right]^{-1}
\end{gathered}
$$

The state space form of the linear model can therefore be expressed by substituting out the Jacobian as follows:

$$
\vec{y}_{t+1}=V \Lambda V^{-1} \vec{y}_{t}+\vec{z}_{t+1}
$$


By isolating the jump variable contained in the above system and imposing the transversality condition, the linear policy function for consumption can be recovered accordingly (see Sims, 2016):

$$
\hat{C}_{t+1}=\left(\frac{1}{\nu_{21}}\right) \hat{K}_{t}+\left(\frac{\nu_{21}-\nu_{23}}{\nu_{21} \cdot \nu_{33}}\right) \hat{X}_{t}+\left(\frac{\nu_{21}-\nu_{23}}{\lambda_{3} \cdot \nu_{21} \cdot \nu_{33}}\right) \varepsilon_{t+1}
$$

Applying a small perturbation from the steady state $t=s s$ and evaluating the derivative gives the immediate response of consumption with respect to an MEI shock (as state variables remained fixed on impact):

$$
\frac{d \hat{C}_{t+1}}{d \varepsilon_{t+1}^{x}}=\frac{\nu_{21}-\nu_{23}}{\lambda_{3} \cdot \nu_{21} \cdot \nu_{33}}=f\left(\alpha, \beta, \delta, \Phi, \eta, \rho_{x}\right)=f(\Omega)=\gamma_{\varepsilon}^{c}
$$

Where, $\Omega=\alpha, \beta, \delta, \Phi, \eta, \rho_{x}$ represents the set of parameters and $\gamma_{\varepsilon}^{c}$ is the coefficient on the MEI shock in the linear policy function for consumption. This gives a closed form expression for the response of consumption on impact in terms of parameters. Imposing a positive response on consumption and solving yields expression (14) in section 4.

$$
\frac{\nu_{21}-\nu_{23}}{\lambda_{3} \cdot \nu_{21} \cdot \nu_{33}}=\gamma_{\varepsilon}^{c} \geq 0 \quad \rightarrow \quad 0 \geq \frac{(1-\alpha)(\alpha+\eta)-(1+\eta) \phi}{(1+\eta)}
$$

The expression above states the subset of the parameter space where consumption increases on impact with respect to an investment shock. However, a second condition is required to resolve the comovement problem. Taking the log-linear labour leisure optimality condition (from table 1A) and substituting out redudent variables gives:

$$
\hat{L}_{t}=\left(\frac{(1-\alpha-\phi)}{\phi(1-\alpha)-(\alpha+\eta)(1-\alpha-\phi)}\right) \hat{C}_{t}-\left(\frac{\alpha(1-\alpha)}{\phi(1-\alpha)-(\alpha+\eta)(1-\alpha-\phi)}\right) \hat{K}_{t}
$$

As capital is fixed on impact of the shock, it can be shown that a univariate relationship exists between current period consumption and current period labour input. Taking the derivative in response to a small perturbation from the steady state $t=s s$ gives:

$$
\frac{d \hat{L}_{s s+1}}{d \hat{C}_{s s+1}}=\frac{(1-\alpha-\phi)}{\phi(1-\alpha)-(\alpha+\eta)(1-\alpha-\phi)}
$$

To be sure that labour moves positively with respect to the investment shock, the chain rule 
is applied for the two derivative expressions above. Applying positivity to ensure labour increases on impact gives expression (16) found in section 4

$$
0 \leq \frac{(1-\alpha-\phi) \gamma_{\varepsilon}^{c}}{\phi(1-\alpha)-(\alpha+\eta)(1-\alpha-\phi)}=\frac{d \hat{L}_{s s+1}}{d \varepsilon_{s s+1}^{x}}
$$

\section{Additional Conditions}

Section B provides conditions for when (12.1) and (12.2) are satisfied. Proof of (12.3) follows directly from applying the chain rule to (16) and by taking the derivative of the linearised production function in the neighborhood of the steady state in Table A3.

$$
\begin{gathered}
\frac{d \hat{Y}_{s s+1}}{d \hat{L}_{s s+1}}=(1-\alpha) \\
\frac{d \hat{Y}_{s s+1}}{d \varepsilon_{s s+1}^{x}}=\frac{(1-\alpha)(1-\alpha-\phi) \gamma_{\varepsilon}^{c}}{\phi(1-\alpha)-(\alpha+\eta)(1-\alpha-\phi)}
\end{gathered}
$$

Moreover, the condition for (12.4) to be satisfied can be derived through taking the derivative of the linearised accounting identity in Table A3 and substituting in the expressions for (12.1) and (12.3) as follows:

$$
\frac{d \hat{Y}_{s s+1}}{d \varepsilon_{s s+1}^{x}}=\left(\frac{C}{Y}\right) \frac{d \hat{C}_{s s+1}}{d \varepsilon_{s s+1}^{x}}+\left(\frac{I}{Y}\right) \frac{d \hat{I}_{s s+1}}{d \varepsilon_{s s+1}^{x}}
$$

Rearranging to make deviations in investment with respect to the shock the subject, and substituting in steady state expressions, yields

$$
\frac{d \hat{I}_{s s+1}}{d \varepsilon_{s s+1}^{x}}=\frac{1-\beta+\beta \delta}{\delta \alpha \beta}\left(\frac{(1-\alpha)(1-\alpha-\phi)}{\phi(1-\alpha)-(\alpha+\eta)(1-\alpha-\phi)}+\frac{1-\beta+\beta \delta}{\delta \alpha \beta}+\phi-1\right) \gamma_{\varepsilon}^{c}
$$

\section{Counter Cyclical labour wedge:}

The labour wedge will always move in the opposite direction to output on impact. This can be shown through consolidating the fixed labour cost and marginal product of labour equations in table A3: 


$$
\hat{\tau}_{t}=-\alpha \hat{K}_{t}+\alpha \hat{L}_{t}-\hat{L}_{t}
$$

Rearranging labour as the subject and differentiating with respect to the labour wedge in the neoubhood of the steady state gives:

$$
\frac{d \hat{L}_{s s+1}}{d \hat{\tau}_{s s+1}}=-\frac{1}{1-\alpha}
$$

Applying the chain rule to eliminate labour gives the relationship between the labour wedge and output on impact:

$$
\frac{d \hat{L}_{s s+1}}{d \hat{\tau}_{s s+1}} \frac{d \hat{Y}_{s s+1}}{d \hat{L}_{s s+1}}=\frac{d \hat{Y}_{s s+1}}{d \hat{\tau}_{s s+1}}=-(1-\alpha) \frac{1}{1-\alpha}=-1
$$
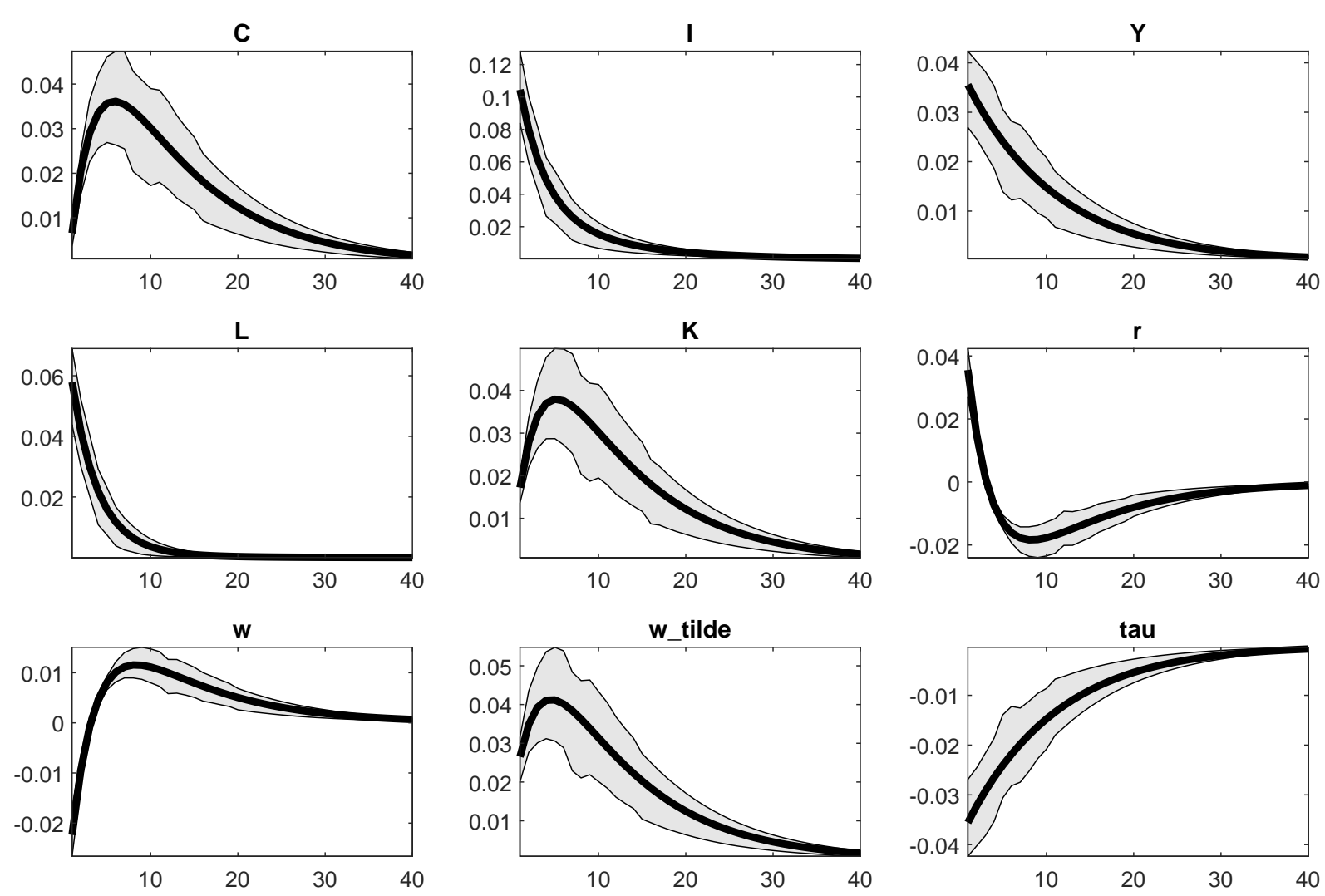

Figure 9: MEI Shock Bayesian IRF with MEI Shock Bayesian

Table A4: Estimated Parameters - Benchmark RBC 


\begin{tabular}{|c|c|c|c|c|c|}
\hline \multirow[t]{2}{*}{ 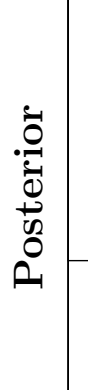 } & $\begin{array}{l}\overline{8} \\
0 \\
0 \\
0 \\
0 \\
0 \\
\vdots \\
0\end{array}$ & $\begin{array}{l} \\
\infty \\
\infty \\
\infty \\
0 \\
\infty \\
0 \\
0 \\
0 \\
0\end{array}$ & $\begin{array}{l}\overline{0} \\
\stackrel{+}{1} \\
0 \\
\dot{0} \\
\infty \\
0 \\
0 \\
0\end{array}$ & $\begin{array}{l}\infty \\
0 \\
0 \\
0 \\
0 \\
0 \\
0 \\
0\end{array}$ & 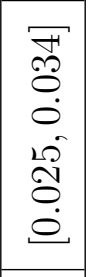 \\
\hline & 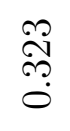 & $\begin{array}{l}\hat{c} \\
\stackrel{0}{c} \\
0 \\
0\end{array}$ & $\begin{array}{l}\sqrt{2} \\
\stackrel{2}{\varrho} \\
0 \\
0\end{array}$ & $\begin{array}{l}\stackrel{H}{0} \\
\stackrel{0}{0}\end{array}$ & $\stackrel{\mathscr{D}}{0}$ \\
\hline \multirow{2}{*}{ 䓒 } & $\stackrel{20}{8}$ & $\stackrel{20}{0}$ & $\stackrel{20}{0}$ & $\underset{-}{\stackrel{-}{8}}$ & \\
\hline & 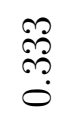 & $\begin{array}{l}\stackrel{\mathscr{m}}{\mathscr{O}} \\
\stackrel{\sigma}{0} \\
0\end{array}$ & $\begin{array}{l}\vec{D} \\
\infty \\
0 \\
0\end{array}$ & $\begin{array}{l}\stackrel{0}{0} \\
\stackrel{0}{0} \\
0\end{array}$ & $\begin{array}{l}\stackrel{2}{\circ} \\
\stackrel{0}{0} \\
0\end{array}$ \\
\hline 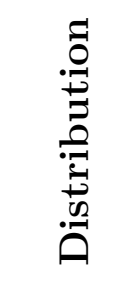 & 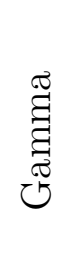 & $\stackrel{\pi}{\stackrel{\pi}{0}}$ & $\stackrel{\pi}{0}$ & 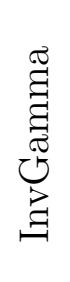 & 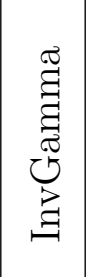 \\
\hline 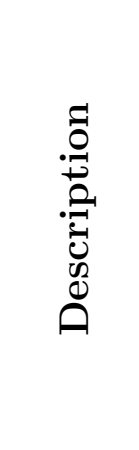 & 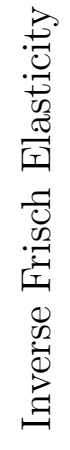 & 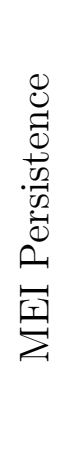 & 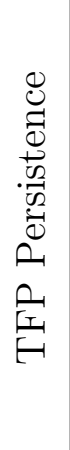 & 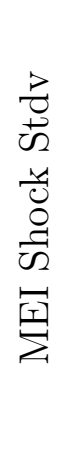 & 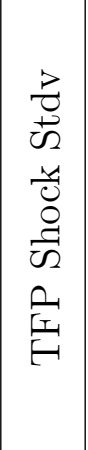 \\
\hline 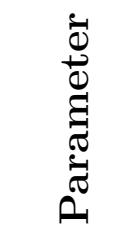 & $=$ & 8 & $\stackrel{8}{a}$ & 0 & 0 \\
\hline
\end{tabular}

\section{References}

[1] Atesagaoglu, O and Elgin, C. (2015). Cyclicality of Labor Wedge and Informal Sector. Economics Letters. 136 (4), 141-146.

[2] Barro, R and King, R. (1984). Time-Separable Preferences and Intertemporal-Substitution Models of Business Cycles. Quarterly Journal of Economics. 99(4), 817-839. 
[3] Chari, V, Kehoe, P and McGrattan, E. (2007). Business Cycle Accounting. Econometrica. $75(3), 781-836$.

[4] Chen, B and Liao, S. (2018). Durable Goods, Investment Shocks, and the Comovement Problem. Journal of Money, Credit and Banking. 50(2), 377-406.

[5] Christiano, L, Eichenbaum, M and Evans, C. (2005). Nominal Rigidities and the Dynamic Effects of a Shock to Monetary Policy. Journal of Political Economy 113(1), 1-45.

[6] Choi, Y (2020). Investment Shocks, Consumption Puzzle, and Business Cycles. Economic Inquiry. 58(3), 1387-1400.

[7] Eusepi, S and Preston, B. (2015). Consumption Heterogeneity, Employment Dynamics and Macroeconomic Co-movement. Journal of Monetary Economics. 71(2), 13-32.

[8] Fisher, J. (2006). The Dynamic Effects of Neutral and Investment-Specific Technology Shocks. Journal of Political Economy. 144(3), 413-451.

[9] Furlanetto, F, Natvik, G and Seneca, M. (2013). Investment Shocks and Macroeconomic Comovement. Journal of Macroeconomics. 37(2), 208-216.

[10] Furlanetto, F and Seneca, M. (2014). Investment Shocks and Consumption. European Economic Review. 66(1), 111-126.

[11] Greenwood, J, Hercowitz, Z and Huffman, G. (1988). Investment, Capacity Utilization, and the Real Business Cycle. American Economic Review. 78(3), 402-417.

[12] Justiniano, A, Primiceri, G and Tambalottic, A. (2010). Investment Shocks and Business Cycles. Journal of Monetary Economics. 57(2), 132-145.

[13] Karabarbounis, L (2014). The Labor Wedge: MRS vs MPN. Review of Economic Dynamics. $17(2), 206-223$.

[14] Khan, H and Tsoukalas, J. (2011). Investment Shocks and the Comovement Problem. Journal of Economics Dynamics and Control. 35(1), 115-130. 
[15] McGrattan, R. and Prescott, E. (2014). A Reassessment of Real Business Cycle Theory. American Economic Review. 104(5), 177-82.

[16] Shimmer, R (2009). Convergence in Macroeconomics: The Labor Wedge. American Economic Journal: Macroeconomics. 1(1), 280-297.

[17] Sims, E (2016). Notes on Solving Linearized Rational Expectations Models. Available at: https://www3.nd.edu/ esims1/linear-rational-expectations-sp16.pdf (accessed: 11 August 2021).

[18] Zhang, L. (2018). Credit Crunches, Individual Heterogeneity and the Labour Wedge. Journal of Macroeconomics. 56(3), 65-88. 